\title{
Rain Damage to Strawberries Grown in Southeast Queensland: Evaluation and Genetic Control
}

\author{
Mark E. Herrington ${ }^{1}$
}

Horticulture and Forestry Science, Agri-Science Queensland, Department of Employment, Economic Development and Innovation, Maroochy Research Station, Nambour, Queensland 4560, Australia

\section{Craig Hardner}

The University of Queensland, School of Agriculture and Food Sciences, Brisbane, Queensland 4072, Australia

\section{Malcolm Wegener}

The University of Queensland, School of Agriculture and Food Sciences, Brisbane, Queensland 4072, Australia

\section{Louella L. Woolcock}

Horticulture and Forestry Science, Agri-Science Queensland, Department of Employment, Economic Development and Innovation, Maroochy Research Station, Nambour, Queensland 4560, Australia

\section{Mark J. Dieters}

The University of Queensland, School of Agriculture and Food Sciences, Brisbane, Queensland 4072, Australia

Additional index words. weather damage, subtropical, etch, cracking, soaking, heritability, Fragaria $\times$ ananassa

Abstract. In Queensland, Australia, strawberries (Fragaria ×ananassa Duchesne) are grown in open fields and rainfall events can damage fruit. Cultivars that are resistant to rain damage may reduce losses and lower risk for the growers. However, little is known about the genetic control of resistance and in a subtropical climate, unpredictable rainfall events hamper evaluation. Rain damage was evaluated on seedling and clonal trials of one breeding population comprising 645 seedling genotypes and 94 clones and on a second clonal population comprising 46 clones from an earlier crossing to make preliminary estimates of heritability. The incidence of field damage from rainfall and damage after laboratory soaking was evaluated to determine if this soaking method could be used to evaluate resistance to rain damage. Narrow-sense heritability of resistance to rain damage calculated for seedlings was low $(0.21 \pm 0.15)$ and not significantly different from zero; however, broad-sense heritability estimates were moderate in both seedlings $(0.49 \pm 0.16)$ and clones $(0.45 \pm 0.08)$ from the first population and similar in clones $(0.56 \pm 0.21)$ from the second population. Immersion of fruit in deionized water produced symptoms consistent with rain damage in the field. Lengthening the duration of soaking of 'Festival' fruit in deionized water exponentially increased the proportion of damage to fruit ranging in ripeness from immature to ripe during the first 6-h period of soaking. When eight genotypes were evaluated, the proportion of sound fruit after soaking in deionized water in the laboratory for up to $5 \mathrm{~h}$ was linearly related $\left(r^{2}=0.90\right)$ to the proportion of sound fruit in the field after $89 \mathrm{~mm}$ of rain. The proportion of sound fruit of the breeding genotype ' 2008 208 ' and 'Festival' under soaking $(0.67,0.60)$ and field $(0.52,0.43)$ evaluations, respectively, is about the same and these genotypes may be useful sources of resistance to rain damage.

In Queensland, 80\% of strawberry (Fragaria $\times$ ananassa) production occurs between Brisbane and the Sunshine Coast with a major

\footnotetext{
Received for publication 23 Nov. 2010. Accepted for publication 4 Mar. 2011.

This project was funded in part by Horticulture Australia Limited (HAL) and Strawberries Australia Inc. (SAI) under projects BS08006 and BS09013.

${ }^{1}$ To whom reprint requests should be addressed; e-mail mark.herrington@deedi.qld.gov.au.
}

concentration in the Wamuran-Caboolture area located $\approx 50 \mathrm{~km}$ north of Brisbane. During the production season, from late fall (May) through early spring (September), rainfall is typically low (mean monthly rainfall $\approx 61$ $\mathrm{mm}$ ), but rainfall events are highly variable. Fruit are exposed to prevailing weather conditions and may suffer rain damage (Herrington and Chandler, 2006).

"Immediate rain damage" on strawberries is expressed during or soon after the rainfall, whereas "delayed rain damage" becomes ob- vious only as the fruit develops 1 week or more after the rainfall (Herrington et al., 2009). "Immediate rain damage" takes the form of "water soaking," etching, and cracking to the stem end (neck, shoulder), body, and tip of affected fruits (Fig. 1). "Delayed rain damage," which requires further investigation, includes a higher than expected proportion of deformed fruit, irregularly cracked fruit, and mottled or blotchy fruit. The investigations reported here are restricted to a consideration of only the "immediate" form of rain damage to strawberries grown in southeast Queensland.

The "immediate rain damage" on strawberry may result from the physical impact of rainfall (i.e., its energy) and/or the water (potential and turgor relationships) derived from the rainfall. Increased turgor caused by rapid uptake of water is the assumed mechanism for rain damage in many fruit species (Opara et al., 1997). Although the energy of impacting raindrops (van Dijk et al., 2002) can be sufficient to bruise "soft" fruit (Holt and Schoorl, 1982), the incidence of high rain damage on some firm-fruited cultivars in southeast Queensland (Herrington et al., 1996) implies that the response of the fruit surface to the free water (i.e., a turgor relationship) rather than the impact of the raindrops per se is probably the major factor influencing resistance to rain damage in strawberry.

Studies in cherry (Prunus avium L.) indicate water uptake by fruit may occur by diffusion through the cuticular membrane, flow through tissue junctures, guard cells or stomatal pores, and through microscopic cracks in the cuticular membrane (Beyer et al., 2005; Peschel and Knoche, 2005). Microscopic cracking of the cuticular membrane is increasingly recognized as an important entry point for water in other fruit (Glenn and Poovaiah, 1989; Knoche et al., 2004) and surface moisture can induce microcracks in the cuticular membrane (Knoche and Grimm, 2008), although their formation is not necessarily related directly to water uptake (Knoche and Peschel, 2006).

Microcracking is exacerbated in european plum (Prunus domestica L. ssp. domestica) by the increased strain that results from developmental features such as fruit expansion and the cessation of cutin deposition in the cuticular membrane with advancing maturity (Knoche and Peschel, 2007). However, we found no specific reports in strawberry on the diffusion of water through the cuticular membrane or the mechanism leading to rain damage. The location on the fruit surface (Gilbert et al., 2007), environmental factors such as surface water or high humidity (Knoche and Peschel, 2006), and cultural factors such as irrigation and fruit thinning (Gilbert et al., 2007) can also influence cracking in other crops.

Rain damage in strawberries typically results in substantial economic losses from rejected fruit as well as increased harvesting, grading, and packing costs coupled with lower prices from reduced consumer demand as a result of poor fruit quality (Herrington et al., 2009). Incorporation of genetic resistance to 


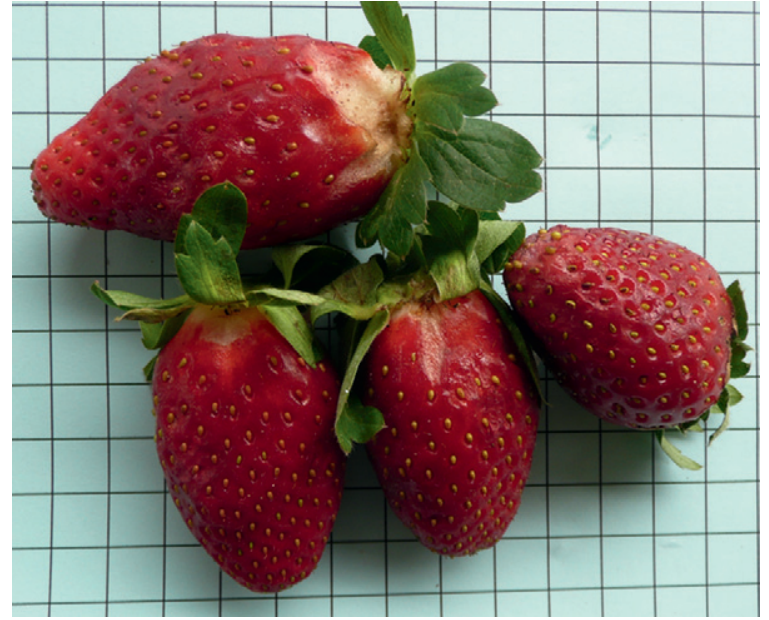

Fig. 1. Rain damage types on fruit: cracking (ring-crack: bottom left; star-crack: bottom center; ring- and star: crack upper). Etch (on tip at bottom right; on body at bottom center).

rain damage into strawberry cultivars released for commercial production in southeast Queensland will reduce both the risk and severity of these losses.

The studies reported here estimate the genetic control (i.e., heritability) of resistance to rain damage, particularly damage resulting from water soaking and surface etching because initial observations indicated that these were the most frequent damage types. However, even if selectable genetic variance exists, selection for resistance relies on the occurrence of sufficient rainfall at an appropriate stage of fruit maturity so that degrees of resistance among genotypes can be determined. The uncertainty of such rainfall events makes selection for resistance in the field difficult. An indirect method to evaluate resistance to rain damage (in the absence of a rain event) would therefore be useful. Soaking fruit in water has been used to simulate rain damage in apples [Malus Xsylvestris (L.) Mill. var. domestica (Borkh.) Mansf.] in a controlled manner (Byers et al., 1990) and cherries (Glenn and Poovaiah, 1989), but such methods have not been applied to strawberry. We therefore conducted an additional series of experiments to test if soaking fruit in deionized water may approximate rain damage sufficiently to be used as an indirect assessment method in strawberry breeding.

\section{Materials and Methods}

\section{Genetic control}

Genetic material. Two sets of genetic material were used to study the genetic control of rain damage. The first included seedling and clonal material. The 23 base parents (four cultivars used commercially in the region and 19 advanced breeding lines that had previously been selected for productivity and fruit quality) were intercrossed to produce 35 full-sib families (i.e., an incomplete factorial) and a total of 645 seedling plants (i.e., genotypes). Each full-sib family was represented in the seedling trial (referred to as "seedling trial I") by five to 77 plants (depending on the success of crossing, germination, and establishment rates) with an average number of 19 seedlings per family.

A sample of seedlings was multiplied vegetatively from 21 of these same 35 families (involving 14 of the 23 parents) with each family represented by one to 13 clones (depending on multiplication rates) with an average of 4.5 clones representing each family. A total of 94 clones were included in the field "clonal trial I."

The second set of material (referred to as the "clonal trial II") comprised runners multiplied vegetatively from a sample of single plants taken from seedlings that had been selected for quality characteristics in 2007. These were the progeny of 27 parents in 30 full-sib families (incomplete factorial) with a total of 46 clones (i.e., individual genotypes) with each family represented by one to five clones (average of 1.5 clones per family).

Production of planting stock and field establishment. After germination in a coir/ vermiculite mix, seedlings were transferred to plugs at the three true-leaf stage and fieldplanted on 6 Mar. 2008 (i.e., "seedling trial I"). For clones, individual seedling plants were dug from the field and established in 10 -L pots in a screenhouse in early spring (Oct. 2008). Runners produced on these plants were grown in plugs in the screenhouse until planted the next year in the field (7 Apr. 2009 for "clonal trial I"). The other set of genetic material (also clones) was planted in the field the previous year on 17 Mar. 2008, "clonal trial II." All field trials were grown in double rows at $26-\mathrm{cm}$ interrow and $40-\mathrm{cm}$ intrarow spacing on $70-\mathrm{cm}$ wide black polythene beds with $140-\mathrm{cm}$ centers and trickle irrigation. Ripe fruit were harvested weekly. Rainfall data were obtained from $<$ http://www.bom. gov.au/climate/data/weather-data.shtml $>$ for the weather station "040988," which was located within $200 \mathrm{~m}$ of the field site where these three trials were grown at Maroochy Research Station in southeast Queensland.

Field design and measurements. "Seedling trial I" was laid out as a partially replicated design with three families present in two replicates and the remaining 32 families in either of the two replicates. Each of the 645 seedling plants (i.e., genotypes) was visually scored for resistance to rain damage between 6 and 8 Sept. 2008 after a 2-d rain event of $120 \mathrm{~mm}$ (4 Sept., $30 \mathrm{~mm}$ and 5 Sept., $90 \mathrm{~mm}$ ). The resistance to rain damage was scored from $1=$ highly damaged (highly susceptible) through $9=$ no damage (highly resistant) based on the estimated percentage of ripe fruit that was sound (i.e., undamaged). Within plots, at least $50 \%$ of plants were sampled so that, depending on plot size, five to 40 genotypes were sampled in each plot with an average of 19 seedlings scored per plot.

"Clonal trial I" was planted in a randomized complete block design with one replicate (plot) of each clone in each of three blocks. Each plot in each block contained four plants (i.e., ramets, the vegetatively multiplied plants of a clone). After a rain event of $89 \mathrm{~mm}$ over $3 \mathrm{~d}$ from 21 to early 23 June 2009, we harvested and counted damaged and sound (i.e., undamaged) fruit from each plot and then calculated the proportion of fruit that were sound. We used the proportion of fruit that were sound because: 1) rain-damaged fruit are unmarketable and so the proportion of fruit that is sound should be an appropriate measure to describe resistance to rain damage; 2) it had been used in rain damage evaluations in a number of other crops e.g., blueberries (Vaccinium ashei Reade) (Marshall et al., 2007); and 3) earlier work in strawberry (unpublished data) had shown that scores for resistance to rain damage were highly correlated $\left(r^{2}=0.89\right)$ with the proportion of sound fruit.

"Clonal trial II" was planted in a randomized complete block design with one replicate (plot) of all clones in each of two blocks. Each plot in each block contained six ramets of a clone. Forty-six clones from 30 families were evaluated with nine clones from eight families present in both blocks and 37 clones present in only a single block to give a total of 55 plots. After a rain event of $64 \mathrm{~mm}$ over $3 \mathrm{~d}$ from 6 to early 8 July 2008, we harvested and counted damaged and sound fruit from each plot and then calculated the proportion of fruit that was sound. In both "clonal trial I" and "clonal trial II," data from plots with less than five fruit were excluded from analyses as a result of the small size of these samples. Note that in all assessments of rain damage, increasing values represent reduced damage or increased resistance to rain damage.

Data analysis. In "seedling trial I," to determine the significance of genotypic effects, we analyzed the resistance to rain damage scores for the seedling data according to the following general mixed linear model:

$$
\mathbf{y}=\mathbf{X b}+\mathbf{Z}_{\mathbf{a}} \mathbf{a}+\mathbf{Z}_{\mathbf{f}} \mathbf{f}+\mathbf{e}
$$

where $\mathbf{y}$ was a vector of observations on a phenotypic trait (here, rain damage resistance score), b was a vector of fixed effects (here, general mean and replicates), a was a vector of random genetic effects of individual genotypes, $\mathbf{f}$ was a vector of random full-sib family effects, and e was a vector of random 
residual terms. $\mathbf{X}, \mathbf{Z}_{\mathbf{a}}$, and $\mathbf{Z}_{\mathbf{f}}$ were the known incidence matrices relating the observations in $\mathbf{y}$ to effects $\mathbf{b}$, a, and $\mathbf{f}$, respectively. The random effects in the model were assumed to follow a multivariate normal distribution such that:

$$
\operatorname{Var}(\mathbf{y})=\mathbf{Z}_{\mathrm{a}} \mathbf{G}_{\mathrm{a}} \mathbf{Z}_{\mathrm{a}}^{\mathrm{T}}+\mathbf{Z}_{\mathrm{f}} \mathbf{G}_{\mathrm{f}} \mathbf{Z}_{\mathrm{f}}^{\mathrm{T}}+\mathbf{R}_{\mathrm{e}}
$$

where $\operatorname{Var}(\mathbf{y})$ was the variance in phenotypic trait "y," $\mathbf{Z}_{\mathrm{a}}^{\mathrm{T}}$ and $\mathbf{Z}_{\mathrm{f}}^{\mathrm{T}}$ denoted transpose matrices of $\mathbf{Z}_{\mathrm{a}}$ and $\mathbf{Z}_{\mathrm{f}}$ respectively; $\mathbf{G}_{\mathrm{a}}=$ $\mathbf{A} \sigma_{\mathrm{a}}{ }^{2}$ in which $\mathbf{A}$ denoted the additive genetic (numerator) relationship matrix that was constructed from pedigree relationships (Mrode, 2005) and $\sigma_{\mathrm{a}}^{2}$ the additive genetic variance; $\mathbf{G}_{\mathrm{f}}=\mathbf{I}_{\mathrm{f}} \sigma_{\mathrm{f}}^{2}$ where $\mathbf{I}_{\mathrm{f}}$ denoted the identity matrix of full-sib families and $\sigma_{\mathrm{f}}^{2}$ was the variance between full-sib families; and $\mathbf{R}_{\mathrm{e}}$ denoted the covariance matrix for the vector of residual errors.

To determine the significance of genotypic effects for data from "clonal trial I" and "clonal trial II," we analyzed the proportion of fruit sound according to the following general mixed linear model:

$$
\mathbf{y}=\mathbf{X b}+\mathbf{Z}_{\mathrm{g}} \mathbf{g}+\mathbf{e}_{\mathrm{c}}
$$

where $\mathbf{y}$ was a vector of observations on a phenotypic trait (here, proportion of sound fruit), $\mathbf{b}$ was a vector of fixed effects (general mean and replicates), $\mathbf{g}$ was a vector of total (i.e., additive + non-additive) genetic effects (here, random genetic effects of individual genotypes), and $\mathbf{e}_{\mathbf{c}}$ was a vector (here, random residual terms). $\mathbf{X}$ and $\mathbf{Z}_{\mathbf{g}}$ were the known incidence matrices relating the observations in $\mathbf{y}$ to effects $\mathbf{b}$ and $\mathbf{g}$, respectively. The random effects in the model were assumed to follow multivariate normal distribution such that:

$$
\operatorname{Var}(\mathbf{y})=\mathbf{Z}_{\mathrm{g}} \mathbf{G}_{\mathrm{g}} \mathbf{Z}_{\mathrm{g}}^{\mathrm{T}}+\mathbf{R}_{\mathrm{ec}}
$$

where $\operatorname{Var}(\mathbf{y})$ was the variance in phenotypic records; $\mathbf{Z}_{\mathrm{g}}^{\mathrm{T}}$ denoted the transpose matrix of $\mathbf{Z}_{\mathrm{g}} ; \mathbf{G}_{\mathrm{g}}=\mathbf{I}_{\mathrm{g}} \boldsymbol{\sigma}_{\mathrm{g}}{ }^{2}$ where $\mathbf{I}_{\mathrm{g}}$ denoted the identity matrix of clones and $\sigma_{\mathrm{g}}{ }^{2}$ was the variance between clones; and $\mathbf{R}_{\mathrm{ec}}$ denoted the covariance matrix for the vector of residual errors.

The variance components were estimated by restricted maximum likelihood (REML; Patterson and Thompson, 1971) using the average information algorithm (Gilmour et al., 1995) implemented in the ASReml program (Gilmour et al., 2006). REML estimation assumes data follow a normal distribution; however, although data from "clonal trial I" were about normally distributed, the rain damage scores were skewed toward damage in the cases of both "seedling trial I" and "clonal trial II." Nevertheless Westfall (1987) found that REML is a good choice in many cases where data are non-normal, and Banks et al. (1985) report that REML variance component estimates are robust to deviations from normality. Therefore, to avoid potential issues associated with interpretation and backtransformation when using transformed data (see for example Dieters et al., 1996), and as a result of robustness of REML to violation of normality, the untransformed rain-damaged scores were used in all analyses.
Additive genetic effects were not estimated for the two clonal trials because with few parental combinations in both, the additive genetic (numerator) relationship matrix (A) derived by including the pedigree (Mrode, 2005) was sparse. Preliminary analysis of seedlings indicated significant spatial variation was not present. Log likelihood ratio tests (Lynch and Walsh, 1998) were used to determine the significance of the estimated variance components of random factors.

Estimation of heritability. To investigate the relative importance of the genetic effects in the seedlings, individual narrow- and broadsense heritability were estimated. Narrow-sense heritability $\left(\hat{h}^{2}\right)$ was estimated as:

$$
\hat{h}^{2}=\frac{\hat{\sigma}_{a}^{2}}{\hat{\sigma}_{a}^{2}+\hat{\sigma}_{f}^{2}+\hat{\sigma}_{e}^{2}}
$$

where $\hat{\sigma}_{a}^{2}$ was the estimated additive genetic variance between individual genotypes, $\hat{\sigma}_{f}^{2}$ was the estimate of the variance between full-sib families, and $\hat{\sigma}_{e}^{2}$ was the estimate of the residual variance within full-sib families. Individual broad-sense heritability $\left(\hat{H}^{2}\right)$ was estimated as:

$$
\hat{H}^{2}=\frac{\hat{\sigma}_{G}^{2}}{\hat{\sigma}_{a}^{2}+\hat{\sigma}_{f}^{2}+\hat{\sigma}_{e}^{2}}
$$

where $\hat{\sigma}_{G}^{2}$ was the estimate for the total genetic variance and estimated as:

$$
\hat{\sigma}_{G}^{2}=\hat{\sigma}_{a}^{2}+4 \hat{\sigma}_{f}^{2} \text {. }
$$

It was assumed that the variation among full-sib families provided an estimate of onefourth of the dominance genetic variation and that epistatic variance was negligible (Falconer and Mackay, 1996).

For "clonal trial I" and "clonal trial II," broad-sense heritability $\left(\hat{H}^{2}\right)$ was estimated as:

$$
\hat{H}^{2}=\frac{\hat{\sigma}_{G c}^{2}}{\hat{\sigma}_{G c}^{2}+\hat{\sigma}_{e c}^{2}}
$$

where $\hat{\sigma}_{G c}^{2}$ is an estimate of the total genetic variance and $\hat{\sigma}_{e c}^{2}$ was the estimate of the residual variance for clones. The SEs of the heritability estimates were calculated within the ASReml program (Gilmour et al., 2006) according to the general expression for the variance of a ratio based on the approximation using the first-order Taylor series expansion (Dieters et al., 1995b; Kendall et al., 1987; Lynch and Walsh, 1998).

\section{Laboratory assessments}

We evaluated the impact of soaking fruit in deionized water in two separate experiments to determine if this could be used to simulate the damage to fruit that occurs under field conditions.

Expt. 1: 'Festival' at different maturities and durations of soaking. On 19 Aug. 2009, we harvested fruit of 'Festival' from the Maroochy Research Station 1 week after the previous harvest. Each fruit was separated using external color into one of six maturity classes based on the number of days before "eating ripe" (i.e., 'M-4' is $4 \mathrm{~d}$ before "eating ripe" and ' $\mathrm{M}+1$ ' is $1 \mathrm{~d}$ after "eating ripe"). Ten fruit were randomly allocated to four replicates within each maturity class. Fruit for each treatment within replicate were placed into a 1-L polypropylene container. The containers were filled with deionized water at room temperature, sealed with the lid to eliminate air gaps, and allowed to stand on the bench-top.

At hourly intervals for the first $6 \mathrm{~h}$ after immersion, we recorded the number of fruit showing "water-soak" damage for each container. Fruit were placed in fresh deionized water and containers resealed after each inspection. Regression approaches in GenStat 11th Ed. (GenStat, 2008) were used to test if there were significant relationships among soaking time, maturity, and the proportion of sound fruit.

Expt. 2: Duration of soaking and comparison with field performance. To provide genotypes for comparison of soaking with field performance, we grouped the 94 clones from "clonal trial I" (see previous sections of "Materials and Methods") into five categories of their resistance to rain damage (proportion of sound fruit) determined after a 3-d, 89-mm rainfall event ending on 23 June 2009 . We then randomly selected two clones from each category and used their proportion of sound fruit as the measure of field performance.

We replanted these 10 representative clones, i.e., '2008-203', '2008-208', '2008219', '2008-241', '2008-251', '2008-254', '2008-289', '2008-296', '2008-306', '2008323', plus commercial cultivars Festival and Rubygem on Maroochy Research Station on 19 Mar. 2010 in a randomized complete block design trial (hereafter referred to as the "soak 2010" trial) with one plot of each clone in each of the five blocks. Each plot in each block contained six ramets of a clone. Runner production and cultural practices were the same as described for "clonal trial I" (see previous sections of "Materials and Methods").

On 9 Aug. 2010, we harvested fruit from each of the five replicates but excluded clones '2008-219', '2008-241', and 'Rubygem' because they did not meet the fruit number specifications (i.e., we included only those genotypes when each plot had at least five fruit of maturity consistent with that of "commercial harvest"). Before soaking, we marked any areas of damage on fruit with a permanent marking pen so that these areas could be separated from damage caused by the soaking and ignored in subsequent assessments. We then placed 10 fruit from each field plot into 1-L polypropylene containers, filled with deionized water, sealed, and allowed to stand at room temperature.

During the $5 \mathrm{~h}$ after immersion, at 1.25 hourly inspections, we removed and noted the number of fruit showing damage from each container. The sound fruit were placed in fresh deionized water and containers resealed after each inspection. The proportion of sound fruit among genotypes was analyzed using a repeated-measure analysis 
of variance for soaking times. The association between the mean proportion of sound fruit for clones from the field rain event and that to $5 \mathrm{~h}$ soaking in the laboratory was evaluated by regression in GenStat 11th Ed. (GenStat, 2008).

\section{Results}

\section{Genetic control}

Residuals from the analysis were generally normally distributed for the analyses of proportion of sound fruit from both the "seedling" and the subsequent "clonal trial I" and from "clonal trial II." Replicate effects were significant ( $F \leq 0.01)$ only in "clonal trial II." Estimated narrow-sense heritability $( \pm \mathrm{SE})$ in seedlings was 0.21 ( \pm $0.15)$, and broad-sense heritability was 0.49 $( \pm 0.16)$. Broad-sense heritability estimated from "clonal trial I" was $0.45( \pm 0.08)$ and from "clonal trial II" was $0.56( \pm 0.21)$.

\section{Laboratory assessments}

'Festival' at different maturities and durations of soaking. Increasing fruit maturity and lengthening the duration of soaking each reduced the proportion of sound fruit (Fig. 2) with little or no interaction (F test $P=$ $0.06)$. After $1 \mathrm{~h}$ of soaking, all fruit in the "M+1" maturity class were damaged and so this maturity class was not included in the analysis. The relationship (F test regression; $P \leq 0.01)$ between the proportion of sound fruit (y) and the duration ( $\mathrm{x}$ ) of soaking to $6 \mathrm{~h}$ and maturity stage $\left(\mathrm{B}_{\mathrm{m}}\right)$ was exponential and described $\left(r^{2}=0.90\right)$ by $\mathrm{y}=\mathrm{A}+\mathrm{B}_{\mathrm{m}}\left(\mathrm{R}^{\mathrm{x}}\right)$ where $( \pm \mathrm{SE}) \mathrm{A}=0.01( \pm 0.04)$ to $0.50( \pm$ $0.02) ; \mathrm{B}_{\mathrm{m}}=0.48( \pm 0.10)$ to $1.17( \pm 0.37)$; and $\mathrm{R}=0.29( \pm 0.09)$ to $0.84( \pm 0.08)$.

At the fruit maturity "M-0" (day of eating ripe), the proportion of sound fruit was only 0.07 after only $1 \mathrm{~h}$ of soaking. This was much less [maturity least significant difference (LSD) $P=0.05=0.12]$ than the proportion of sound fruit $(0.83)$ at the lesser fruit maturity "M-4" (4 d before eating ripe). The first hour of soaking resulted in an average reduction in the proportion of sound fruit of nearly half $\left(0.45\right.$, soaking time $\left.\operatorname{LSD}_{P}=0.05=0.06\right)$. Apart from this, the largest average decreases in the proportion of sound fruit (Fig. 2) came between maturity "M-1" and "M-2" (0.24), "M-3" and "M-4" (0.22), and between time 1 and $2 \mathrm{~h}(0.21)$

Duration of soaking and comparison with field performance. After soaking, the 12 genotypes tested (Table 1) exhibited symptoms of water-soaking and etch on the fruit surface similar in appearance to those observed after rain in the field. Fine surface cracks were also present and tended to coalesce into longer cracks, which could be considered similar to body cracks. Starcracking was also present in $7 \%$ of damaged fruit.

Increasing the duration of soaking up to $5 \mathrm{~h}$ significantly reduced the proportion of sound fruit. The interaction of time and genotype was not significant. The effect of genotype was highly significant and the

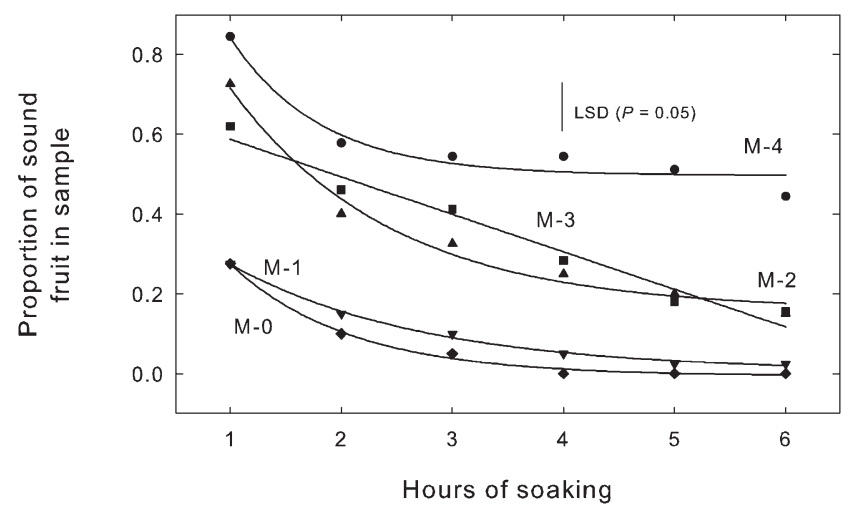

Fig. 2. Proportion (y) of 'Festival' fruit of five levels of maturity that remained sound after six durations (x) of soaking in deionized water. Each datum point is the mean of four replicates each of 10 fruit. Maturity is days, from $4 \mathrm{~d}(\mathrm{M}-4)$ before until eating ripe $(\mathrm{M}-0)$. Regression equations $( \pm \mathrm{SE})$ : $\mathrm{y}_{(\mathrm{M}-0)}=0.71( \pm$ $0.21) \times 0.40( \pm 0.12)^{\mathrm{x}} ; \mathrm{y}_{(\mathrm{M}-1)}=0.01( \pm 0.04)+0.48( \pm 0.10) \times 0.56( \pm 0.13)^{\mathrm{x}} ; \mathrm{y}_{(\mathrm{M}-2)}=0.16( \pm 0.03)+$ $1.11( \pm 0.13) \times 0.50( \pm 0.06)^{\mathrm{x}} ; \mathrm{y}_{(\mathrm{M}-3)}=0.22( \pm 0.33)+0.98( \pm 0.28) \times 0.84( \pm 0.08)^{\mathrm{x}} ; \mathrm{y}_{(\mathrm{M}-4)}=0.50$ $( \pm 0.02)+1.17( \pm 0.37) \times 0.29( \pm 0.09)^{\mathrm{x}}$

proportion of sound fruit was highest for breeding genotypes '2008-306' and '2008208', although these were not significantly higher than 'Festival' (Table 1). The proportion of fruit that was sound after the rain event also differed (F test $P<0.05$ ) among genotypes (Table 1).

There was a strong linear relationship $[\mathrm{y}=$ $\left.-0.40+1.49 \mathrm{x}\left(r^{2}=0.90\right)\right]$ between the proportion of sound fruit $(\mathrm{x})$ after soaking in the laboratory and the proportion of sound fruit in the field (y) after a 89-mm rain event (Fig. 3).

\section{Discussion}

\section{Genetic control}

The narrow-sense heritability estimate for seedlings $(0.21 \pm 0.15)$ had a large SE and so should only be considered indicative. This estimate implies a low response to phenotypic selection for resistance to rain damage with the need for progeny testing. The three estimates of broad-sense heritability $(0.49 \pm$ $0.16,0.45 \pm 0.08$, and $0.56 \pm 0.21$ from "seedling trial I," "clonal trial I," and "clonal trial II," respectively) are consistent with each other and all significant. These are the first heritability estimates for rain damage in strawberry. When compared with the estimate of narrow-sense heritability, the estimates of broad-sense heritability suggest that non-additive variance may be of similar magnitude to additive variance for rain damage in this strawberry population. Further work with larger data sets is required to validate the estimates presented here.

Estimation of variance components with REML assumes data are normally distributed (as indicated previously). Estimates in our case are likely to be upwardly biased as a result of confounding effects of genotype $x$ environment interaction (e.g., Dieters et al., 1995a). By contrast, the number of fruits on which the proportion of sound fruit was based in the seedlings (fruit per plant) and clones (fruit per plot) was sometimes low and may have inflated residual variance estimates, thus lowering estimated heritability.
Table 1. Proportion of fruit remaining sound following soaking for up to $5 \mathrm{~h}$ and after 89$\mathrm{mm}$ rainfall in the field. ${ }^{\mathrm{z}}$

\begin{tabular}{lcc}
\hline & \multicolumn{2}{c}{ Proportion of fruit sound zy $^{z y}$} \\
\cline { 2 - 3 } Genotype & $\begin{array}{c}\text { Soaking } \\
\text { evaluation }\end{array}$ & $\begin{array}{c}\text { Rainfall in } \\
\text { the field }\end{array}$ \\
\hline $2008-208$ & $0.67 \mathrm{a}$ & $0.60 \mathrm{c}$ \\
$2008-306$ & $0.61 \mathrm{a}$ & $0.56 \mathrm{bc}$ \\
Festival & $0.52 \mathrm{abc}$ & $0.43 \mathrm{abc}$ \\
$2008-203$ & $0.56 \mathrm{ab}$ & $0.33 \mathrm{abc}$ \\
Rubygem & $\mathrm{NT}$ & $0.22 \mathrm{abc}$ \\
$2008-296$ & $0.34 \mathrm{~d}$ & $0.20 \mathrm{abc}$ \\
$2008-254$ & $0.42 \mathrm{bcd}$ & $0.20 \mathrm{abc}$ \\
$2008-219$ & $\mathrm{NT}$ & $0.12 \mathrm{ab}$ \\
$2008-241$ & $\mathrm{NT}$ & $0.11 \mathrm{ab}$ \\
$2008-289$ & $0.35 \mathrm{~d}$ & $0.10 \mathrm{a}$ \\
$2008-251$ & $0.30 \mathrm{~d}$ & $0.00 \mathrm{a}$ \\
$2008-323$ & $0.40 \mathrm{~cd}$ & $\mathrm{NT}$ \\
LSD $_{P}=0.05$ & 0.15 & 0.45 \\
\hline
\end{tabular}

${ }^{2}$ Within columns, the data followed by a letter in common are not significantly different by analysis of variance with the least significant difference (LSD) $(P=0.05)$ test (GenStat, 2008).

${ }^{y}$ Data on are means of proportion of sound fruit from five replicates: for soaking evaluation at the four assessment times of $1.25,2.5,3.75$, and $5 \mathrm{~h}$ after fruit were first immersed; and for field after $89 \mathrm{~mm}$ of rain. In each replicate, 10 fruit were evaluated in soaking evaluation and at least five in the field trial.

$\mathrm{NT}=$ not tested.

For comparison, the optimal number of fruit to evaluate resistance to cracking in cherry was 40 (Hansche and Beres, 1966). However, biological limitations in strawberries prevent larger sample sizes; increasing minimum fruit number above five would have led to a much larger number of missing values. Additionally, the data for the seedlings and clones were produced from separate single rainfall events. These difficulties in field evaluation support the need for an indirect method to evaluate resistance to rain damage.

\section{Laboratory assessments}

'Festival' at different maturities and durations of soaking. Symptom expression consistent with that of rain damage under field 


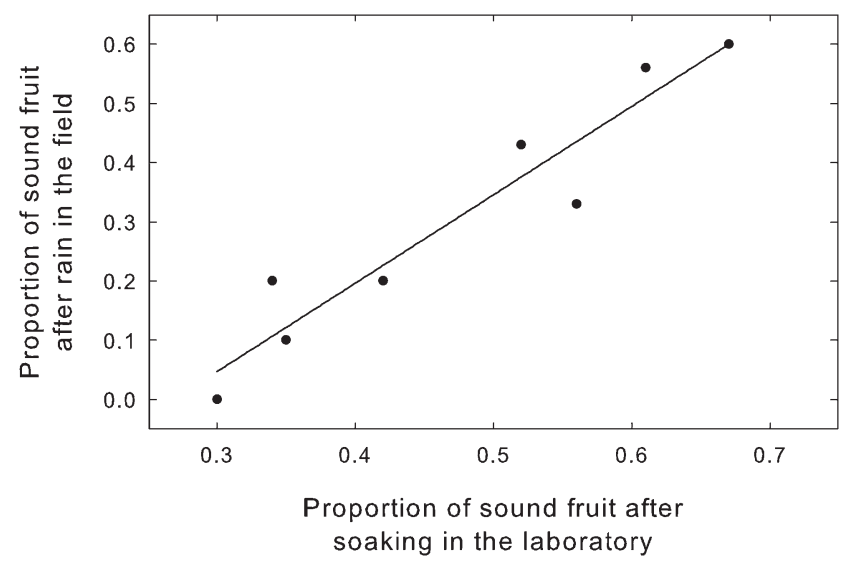

Fig. 3. Correlation of proportion of sound fruit after soaking in deionized water in the laboratory $(\mathrm{x})$ and the proportion of sound fruit in the field after a $89-\mathrm{mm}$ rain event $(\mathrm{y})$. Regression equation $( \pm \mathrm{SE}): \mathrm{y}=-0.40$ $( \pm 0.09)+1.49( \pm 0.19) \times\left(r^{2}=0.90 ; \mathrm{F}\right.$ test regression; $\left.P \leq 0.001\right)$.

conditions suggests that a laboratory soaking treatment may be an effective indirect method for screening for rain damage and provides an alternative to evaluation of fruit after a rainfall event. The substantial effect of maturity and duration of soaking (Fig. 2) on damage could help explain some of the variation in the extent of rain damage among fields and rain events (Herrington et al., 2009).

The higher susceptibility of fruit at greater maturity is consistent with that found in cherry (Moing et al., 2004) and may be related to the incidence of microcracks in the cuticular membrane like in cherry (Glenn and Poovaiah, 1989) and grape (Vitis vinifera L.) (Considine, 1982). Microcracks increase with increasing maturity and thereby allow more water to enter the fruit (Knoche and Peschel, 2006). The consequent strain in a fruit surface is related to shape (Considine and Brown, 1981). Because of the uneven surface topography in strawberry, the overall relationship would more be complex than the theoretical model or for smooth skinned fruit like cherry and grape but could help describe the local effects e.g., longitudinal, and ring fractures in the cuticle are predicted for long (prolate) spheroidal and flattened (oblate) spheroidal shapes, respectively. Star-cracking is predicted to occur at an unreinforced hole in the surface of a membrane and is commonly a secondary failure after primary ring-cracking, which later creates a nominal threefold increase in stress tangential to the hole (Considine and Brown, 1981). The junctions of differing tissue types, e.g., the external location of seed in strawberry, will likely also change strain relationships and water permeability. Because of the significance of microcracking's contribution to rain damage in other crops, an investigation of microcracking in strawberry is warranted. Initial studies could use an $\times 100$ fluorescence microscopy procedure (Knoche and Peschel, 2006) to compare the frequency of microcracks, with and without immersion, on strawberry genotypes differing in resistance to rain damage.

The durations of soaking in water recommended for use to simulate evaluation of the resistance of fruit to rain-induced cracking and splitting in other crops have varied from $14 \mathrm{~h}$ for blueberries (Marshall et al., 2007) to $4 \mathrm{~h}$ for cherries (Harding, 1983). Evaluation conditions that produce a sufficient (greater than $\approx 0.3$ ) but not excessive (less than $\approx 0.95$ ) proportion of undamaged fruit on the moderately resistant 'Festival' are likely to allow effective discrimination between moderately work found such conditions varied with duration of soaking and maturity of fruit (Fig. 2). Consequently, we suggest that with strawberry fruit of maturity of "eating ripe" ("M-0") or "1 d before eating ripe" ("M-1"), soaking fruit for $1 \mathrm{~h}$ is suitable for evaluation of potential rain damage. Additionally, for fruit of maturities from 2 to $4 \mathrm{~d}$ before "eating ripe," $3 \mathrm{~h}$ of soaking is suitable. Fruit more mature than "eating ripe" had a very high proportion damaged in all durations of soaking studied and should not be used.

Duration of soaking and comparison with field performance. The consistency of symptoms between laboratory soaking (water soaking, which on drying results in surface etching) and rain damage in the field (surface etching) and the strong association $\left(r^{2} \approx 0.90\right)$ between the proportion of undamaged fruit from soaking and that from a field rainfall event indicate that soaking can be used to evaluate resistance to rain damage in strawberry. This is true also with blueberries (Marshall et al., 2007) and cherries (Harding, 1983). Because the indirect assessment method avoids many confounding effects of field evaluation, it may well improve estimates of heritability. It will be useful for eliminating many susceptible genotypes in early stages, even if additional field tests are required to confirm resistant genotypes. Of additional interest for breeding is that under these experimental soaking conditions, genotypes '2008-306' and '2008-208', whose levels of most production and quality traits are similar to 'Festival', had a high proportion of sound fruit ( 0.61 and 0.67 , respectively), although not significantly greater than 'Festival' (0.52). 'Festival' has been considered by resistant and susceptible cultivars. Our present growers to have a level of resistance to rain damage greater than many other available cultivars.

\section{Literature Cited}

Banks, B.D., I.L. Mao, and J.P. Walter. 1985. Robustness of the restricted maximum likelihood estimator derived under normality as applied to data with skewed distributions. J. Dairy Sci. 68:1785-1792.

Beyer, M., S. Lau, and M. Knoche. 2005. Studies on water transport through the sweet cherry fruit surface: IX. Comparing permeability in water uptake and transpiration. Planta 220:474-485.

Byers, R.E., D.H. Carbaugh, and C.N. Presley. 1990. 'Stayman' fruit cracking as affected by surfactants, plant growth regulators, and other chemicals. J. Amer. Soc. Hort. Sci. 115:405411.

Considine, J. and K. Brown. 1981. Physical aspects of fruit growth-Theoretical analysis of distribution of surface growth forces in fruit in relation to cracking and splitting. Plant Physiol. 68:371-376

Considine, J.A. 1982. Physical aspects of fruit growth: Cuticular fracture and fracture patterns in relation to fruit structure in Vitis vinifera. J. Hort. Sci. 57:79-91.

Dieters, M.J., T.L. White, and G.R. Hodge. 1995a. Genetic parameter estimates for volume from full-sib tests of slash pine (Pinus elliottii). Can. J. For. Res. 25:1397-1408.

Dieters, M.J., T.L. White, R.C. Littell, and G.R. Hodge. 1995b. Application of approximate variances of variance components and their ratios in genetic tests. Theor. Appl. Genet. 91:15-24.

Dieters, M.J., G.R. Hodge, and T.L. White. 1996. Genetic parameter estimates for resistance to rust (Cronartium quercuum) infection from fullsib tests of slash pine (Pinus elliottii), modelled as functions of rust incidence. Silvae Genet. 45: 235-242.

Falconer, D.S. and T.F.C. Mackay. 1996. Introduction to quantitative genetics. Longman Group Limited, Harlow, UK.

GenStat. 2008. GenStat. 11th Ed. Lawes Agricultural Trust, Rothamsted, UK.

Gilbert, C., J. Chadoeuf, G. Vercambre, M. Genard, and F. Lescourret. 2007. Cuticular cracking on nectarine fruit surface: Spatial distribution and development in relation to irrigation and thinning. J. Amer. Soc. Hort. Sci. 132:583-591.

Gilmour, A., B. Gogel, B. Cullis, and R. Thompson. 2006. ASReml user guide. Release 2.0. VSN International, Hemel Hempstead, Hampstead, UK.

Gilmour, A.R., R. Thompson, and B.R. Cullis. 1995. Average information REML: An efficient algorithm for variance parameter estimation in linear mixed models. Biometrics 51: 1440-1450.

Glenn, G.M. and B.W. Poovaiah. 1989. Cuticular properties and postharvest calcium applications influence cracking of sweet cherries. J. Amer. Soc. Hort. Sci. 114:781-788.

Hansche, P.E. and V. Beres. 1966. An analysis of environmental variability in sweet cherry. Proc. Amer. Soc. Hort. Sci. 88:167-172.

Harding, P.H. 1983. Testing and cultivar evaluation, p. 371-382. In: Moore, J.N. and J. Janick (eds.). Methods in fruit breeding. Purdue University Press, West Lafayette, IN.

Herrington, M., S. Prytz, G.N. Greer, D.G. Hutton, and J.A. Moisander. 1996. Strawberry cultivar improvement (Queensland-subtropical Australia). Final Report for Horticultural Research and Development Corporation, Project No. Fr143. 
Herrington, M.E. and C.K. Chandler. 2006. Strawberry breeding in a subtropical environment. Acta Hort. 708:441-447.

Herrington, M.E., L. Woolcock, M. Wegener, M. Dieters, and J. Moisander. 2009. Cultivar differences in tolerance to damage by rainfall. Acta Hort. 842:483-486.

Holt, J.E. and D. Schoorl. 1982. Strawberry bruising and energy dissipation. J. Texture Stud. 13: 349-357.

Kendall, M.G., A. Stuart, and J.K. Ord. 1987. Kendall's advanced theory of statistics. Vol. 3, Design and analysis, and time series. Oxford Univ. Press, New York, NY.

Knoche, M., M. Beyer, S. Peschel, B. Oparlakov, and M.J. Bukovac. 2004. Changes in strain and deposition of cuticle in developing sweet cherry fruit. Physiol. Plant. 120:667-677.

Knoche, M. and E. Grimm. 2008. Surface moisture induces microcracks in the cuticle of 'Golden Delicious’ apple. HortScience 43:1929-1931.
Knoche, M. and S. Peschel. 2006. Water on the surface aggravates microscopic cracking of the sweet cherry fruit cuticle. J. Amer. Soc. Hort. Sci. 131:192-200.

Knoche, M. and S. Peschel. 2007. Deposition and strain of the cuticle of developing European plum fruit. J. Amer. Soc. Hort. Sci. 132:597602.

Lynch, M. and B. Walsh. 1998. Genetics and analysis of quantitative traits. Sinauer Associates Incorporated, Sunderland, MA.

Marshall, D.A., J.M. Spiers, S.J. Stringer, and K.J. Curry. 2007. Laboratory method to estimate rain-induced splitting in cultivated blueberries. HortScience 42:1551-1553.

Moing, A., C. Renaud, H. Christmann, L. Fouilhaux, Y. Tauzin, A. Zanetto, M. Gaudillère, F. Laigret, and J. Claverie. 2004. Is there a relation between changes in osmolarity of cherry fruit flesh or skin and fruit cracking susceptibility? J. Amer. Soc. Hort. Sci. 129:635-641.
Mrode, R.A. 2005. Linear models for the prediction of animal breeding values. CABI Publishing, Wallingford, UK.

Opara, L.U., C.J. Studman, and N.H. Banks. 1997. Fruit skin splitting and cracking. Hortic. Rev. 19:217-262.

Patterson, H.D. and R. Thompson. 1971. Recovery of interblock information when block sizes are unequal. Biometrika 31:100-109.

Peschel, S. and M. Knoche. 2005. Characterization of microcracks in the cuticle of developing sweet cherry fruit. J. Amer. Soc. Hort. Sci. 130: 487-495.

van Dijk, A., L.A. Bruijnzeel, and C.J. Rosewell. 2002. Rainfall intensity-kinetic energy relationships: A critical literature appraisal. J. Hydrol. (Amst.) 261:1-23.

Westfall, P.H. 1987. A comparison of variance component estimates for arbitrary underlying distributions. J. Amer. Stat. Assoc. 82:866874 . 